\title{
Hacia un modelo de análisis de la Propaganda Fotográfica
}

\author{
Towards an analysis model of the photographic propaganda
}

\author{
Ana I. Barragán-Romero, Centro Universitario EUSA, Universidad de Sevilla \\ Calle Plácido Fernández Viagas, 4, 41013 Sevilla \\ ana.barragan@eusa.es | Orcid: https://orcid.org/0000-0002-4285-9038
}

DOI: http://dx.doi.org/10.12795/Ambitos.2019.i45.15

\begin{abstract}
Resumen
Los estudios propagandísticos de la fotografía han vinculado frecuentemente la imagen fotográfica con la manipulación de su contenido. Son famosos los casos en los que se ha eliminado a personas de las fotografías, se han realizado montajes, e incluso se ha escenificado un momento histórico. No obstante, este artículo parte de que el verdadero factor que determina si una fotografía puede considerarse propaganda, más allá del contenido de la propia imagen o la edición de la misma, es la intencionalidad del emisor último que hace uso de ella, es decir, el ente que detenta el poder. Para ello, en este artículo se hace un repaso teórico de los principales modelos de análisis de la propaganda (Lasswell (1993); Chomsky y Herman (2005); Jowett \& O'Donnell (2012); Pineda (2006)), y se propone un modelo de análisis que parte de la emisión de la imagen y permite determinar los procesos mediante los cuales una fotografía puede pasar a denominarse Propaganda Fotográfica; entendiendo que el emisor de la fotografía normalmente no coincide con el fotógrafo que captura la imagen. Al mismo tiempo, también se contempla la resemantización de la fotografía gracias a los efectos transformadores del poder. Actualmente, este tema cobra más importancia que nunca, ya que son numerosos los casos de utilización de fotografías
\end{abstract}


fuera de contexto que únicamente sirven a los intereses del organismo que busca conseguir, mantener o reforzar una posición de poder sobre los receptores de las imágenes. De este modo, la conclusión más relevante es que el uso de la Propaganda Fotográfica no se restringiría exclusivamente a contextos totalitarios, sino a situaciones en las que un emisor utilice la fotografía como herramienta propagandística para conseguir o mantener el poder.

\section{Abstract}

The photographic propaganda studies have frequently linked the photographic image with the manipulation of its content. There are famous cases in which people have been removed from the photographs, assemblies have been made, and even a historical moment has been staged. Not often, this article starts from the fact that the true factor that determines whether a photograph can be considered propaganda beyond the content of the image itself or its edition- is the intentionality of the sender, the entity that want to achieve the power. For this, after a review of the main models of propaganda analysis (Lasswell (1993); Chomsky y Herman (2005); Jowett \& O'Donnell (2012); Pineda (2006)), an analysis model is proposed. It starts from the emission of the image and allows to determine the processes by means of which a photograph can be renamed photographic propaganda; understanding that the sender of the photograph does not normally coincide with the photographer who captures the image. At the same time, the resemantization of photography is also contemplated thanks to the transforming effects of power. Currently, this issue is more important than ever, since there are numerous cases of using photographs out of context that only serve the interests of the body that seeks to achieve, maintain or reinforce a position of power over the receivers of the images. Thereby, the main conclusion of this paper is that the use of photographic propaganda would not be restricted exclusively to totalitarian contexts, but to situations in which a sender uses photography as a propaganda tool to achieve or maintain a powerful position.

Palabras clave: propaganda, fotografía, se modelo, análisis, ideología.

Keywords: propaganda, photography, model, analysis, ideology.

\section{INTRODUCCIÓN}

El estudio propagandístico de la fotografía es un terreno abarcado por una gran cantidad de teorías y apreciaciones que, en la mayor parte de los casos, vinculan la imagen fotográfica con la manipulación (Freund, 1983; Jaubert, 1989; Brugioni, 1999; Sousa, 2003; Knightley, 2003; Pérez Gallardo, 2009). La fotografía como medio de representación de la realidad ha sido un área de investigación muy tratada desde que apareció esta técnica. Sin embargo, son pocos los estudios que analizan la imagen fotográfica como herramienta de la propaganda de manera específica. Cuando lo hacen, centran 
dichos usos propagandísticos de la fotografía en las guerras y los totalitarismos del siglo XX, ignorando mayoritariamente los tiempos de paz. Por otro lado, las relaciones de la imagen con la ideología (Bourdieu, 1979, 2003; Knightley, 2003; Sontag, 2009, 2010) añaden (potencialmente) confusión adicional al uso estrictamente propagandístico de ciertas fotografías, ya que las dimensiones e implicaciones ideológicas de lo visual pueden deberse a una multiplicidad de intenciones por parte de quienes las generan. Es por ello que la pertinencia de este artículo se fundamenta en la necesidad de enfocar el estudio de los usos propagandísticos de la fotografía desde el ángulo adecuado: la intencionalidad del emisor último de la imagen fotográfica.

Por ello, la base de la teoría desarrollada en estas páginas parte de la necesaria intencionalidad del emisor para poder determinar que una imagen fotográfica ha sido utilizada propagandísticamente. Con ello no se resta interés a las teorías sobre la recepción y la interpretación de los mensajes; pero defendemos que, para afirmar que una fotografía es usada de manera propagandística, hay que girar el punto de vista hacia el ente que emite la imagen, más allá del contenido de la misma y el tipo de interpretación que hagan los receptores. Existe una gran cantidad de opiniones que el público puede tener sobre un mismo mensaje fotográfico, pero esto no hace que deje de ser propagandístico; del mismo modo, el contenido de la imagen no es condición necesaria para considerarla propagandística, ya que un mismo contenido semántico puede ser usado por emisores distintos con intenciones distintas. Es por ello por lo que en esta investigación establecemos la necesidad de analizar al ente emisor de la imagen fotográfica para poder determinar con seguridad que estamos ante un caso de propaganda. Por tanto, el objetivo general de este estudio es plantear un modelo de análisis que permita estudiar los usos propagandísticos que pueden hacerse de la fotografía, desde el punto de vista (fundamentalmente) de las condiciones de emisión.

Para ello, se sigue una metodología basada fundamentalmente en bibliografía secundaria con el objetivo de elaborar un marco teórico sólido que permita construir las principales variables que se relacionan en el modelo de análisis propuesto. Teniendo presente que este estudio parte de un enfoque propagandístico (y no fotográfico), se hace una revisión de los modelos exclusivos de análisis de la propaganda, destacando entre ellos los de Lasswell (1993), Pineda (2006), Chomsky y Herman (2005) y Jowett y O'Donnell (2012). El modelo propuesto en este estudio parte de la única definición académica propuesta de la Propaganda Fotográfica (Barragán-Romero, 2017), y adopta gran parte de sus variables del modelo semiótico de la propaganda desarrollado por Pineda (2006).

Tras los resultados, en los que se desarrolla con exactitud el planteamiento del modelo de análisis de la propaganda fotográfica, se propone un ejemplo gráfico extraído de la red social Instagram, con el objetivo fundamental de demostrar que esta técnica no es 
exclusiva de contextos totalitarios, sino que es usada diariamente por cualquier candidato político.

\section{MODELOS DE ANÁLISIS DE LA PROPAGANDA}

Willer (1969) sugiere que "un modelo es la conceptualización de un grupo de fenómenos, elaborada mediante un principio racional, cuyo propósito final es suministrar los términos y relaciones -las proposiciones- de un sistema formal que, una vez validado, se convierte en teoría" (p. 44). El autor señala que los elementos que conforman el modelo sólo corresponden a una parte de los fenómenos estudiados, porque "los modelos no son nunca exhaustivos ni describen todos los aspectos de los fenómenos" (1969, pp. 46-47). En este sentido apunta asimismo Rodrigo Alsina (2007), quien afirma que un modelo "siempre será una explicación parcial del fenómeno comunicativo" , (p. 21), puesto que la realidad es simplificada en sus variables más representativas, ya que sería imposible representarla al completo y el modelo dejaría de tener sentido.

En el terreno de la Propaganda Fotográfica, objeto de este estudio, no encontramos ningún modelo que nos permita estudiar la fotografía como herramienta de la comunicación propagandística. Por ello, debemos aludir a los principales modelos históricos que han tenido como propósito explicar el funcionamiento de la propaganda.

Harold D. Lasswell fue el creador del que quizás pueda llamarse el primer modelo de la teoría de la propaganda, definido en "Estructura y función de la comunicación de masas", artículo publicado originalmente en 1948 en The Communication of Ideas bajo el título "The Structure and Functions of Communication in Society" (De Moragas, 1993). El autor estudió la organización de la propaganda en los principales países que estuvieron en conflicto en la Primera Guerra Mundial, por lo que su modelo parte de la teoría de la propaganda y la psicología conductista, que entiende que ante una serie de estímulos se obtienen unas respuestas determinadas. Según Lasswell (1993, p. 51), para describir cualquier acto de comunicación hay que responder a las siguientes preguntas: ¿Quién/ dice qué/ en qué canal/ a quién/ y con qué efecto? Nos encontramos así con un modelo meramente descriptivo y unilineal, en el que el peso de la comunicación recae sobre el emisor, fundamentalmente por la tendencia behaviorista de la que parte, según la cual un mensaje lanzado a través de los medios de comunicación produce unos efectos determinados en la audiencia.

Otro modelo de la propaganda a destacar fue desarrollado en los años ochenta del siglo XX de la mano de Garth S. Jowett y Victoria O'Donnell (2012, pp. 29-30), quienes tenían como objetivo acabar con la confusión entre la propaganda y la persuasión. El objeto de los autores es demostrar que existe una separación entre ambos términos que depende del propósito y el proceso. Parten del concepto de comunicación, que entienden como "a process of exchange in which sender and receiver, either through

Ámbitos. Revista Internacional de Comunicación | ISSN: 1139-1979 | E-ISSN: 1988-5733, №. 45. (2019) 
mediated or nonmediated means, create, acquire, transmit, and use information" (Jowett y O'Donnell, 2012, p. 31). Por su parte, el propósito de la propaganda sería promover una causa partidaria que apoye los intereses del propagandista, pero no necesariamente los del receptor, por lo que la comunicación propagandística excedería el entendimiento mutuo necesario para una comunicación informativa. De esta teoría rescatamos la intencionalidad del emisor, rasgo que destacan los autores como distintivo de la propaganda.

Jowett y O'Donnell (2012, pp. 359-360) desarrollan al mismo tiempo un modelo en el que entienden que la comunicación propagandística es un proceso incluido en un sistema social; un modelo que suponen complejo, como la propaganda misma. De este modo, el proceso de la propaganda tomaría la forma de un mensaje que circula a través de una red, que incluye los agentes propagandísticos, varios medios de comunicación y una red social que comienza con la institución y termina con la posibilidad de respuesta del público o audiencia. Los autores dan especial importancia a examinar el proceso propagandístico en la situación histórico-social en la que se inserta. Del mismo modo, resaltan la importancia de la cultura, porque entienden que cuando la propaganda tiene lugar, impacta potencialmente en la cultura, del mismo modo que la cultura tiene impacto en la propaganda.

El enfoque de partida desde la emisión de la propaganda también puede encontrarse en el modelo de propaganda más conocido en el mundo académico, el elaborado por Noam Chomsky y Edward S. Herman (2005) a finales de los años ochenta, basado en el papel de los medios de comunicación en la sociedad estadounidense de la época. Los guardianes de la libertad (título original: Manufacturing Consent. The Political Economy of the Mass Media) apoya la idea de que los medios son utilizados para consensuar la opinión pública a favor de los intereses privados y estatales. La teoría democrática afirma que "los medios de comunicación son independientes y tienen la obligación de descubrir la verdad e informar de ella, y no reflejar pura y simplemente la percepción del mundo que desearían los grupos de poder" (Chomsky y Herman, 2005, p. 11). Afirma Pineda (2001, p. 193) que la premisa básica del modelo es que las élites corporativas y gubernamentales hacen uso de los medios de masas para hacer llegar mensajes y símbolos propagandísticos a los ciudadanos, incidiendo directamente en su cosmovisión. De este modo, la propaganda de las sociedades democráticas es mucho más apetecible que la que se da en las sociedades dictatoriales, ya que está cubierta de una pantalla de libertad informativa e independencia mediática.

Como último modelo propagandístico cabe destacar el desarrollado por Antonio Pineda (2006), que es definido por el propio autor como "un modelo formal-funcional de alcance universal sobre el mensaje propagandístico" (p. 237). El modelo propone que el mensaje propagandístico es universal porque cuenta con una estructura formal 
compuesta por conceptos abstractos que se van actualizando con cada caso concreto. Pineda (2006, p. 237) entiende que dicha estructura universal puede encontrarse en mensajes de cualquier época. De hecho, Pineda, Barragán y Macarro (2012) demostraron su universalidad al aplicarlo a las portadas de prensa del periódico $A B C$ durante la Guerra Civil Española.

Pineda (2006) señala tres características del modelo. La primera propiedad de esta estructura formal es su universalidad, ya que "está presente en todos los mensajes reconocibles como "propaganda". En segundo lugar, "se trata de una estructura formal comunicacional. Los conceptos abstractos que forman la estructura del Mensaje responden a los otros dos conceptos universales del proceso de la comunicación: Emisor y Receptor" (p. 238). En tercer y último lugar, el enfoque formal-funcional del modelo hace que el autor no lo dote de contenido alguno. A fin de cuentas, estamos ante "un modelo conceptual-analítico, cuyo objetivo es el análisis de las relaciones que existen entre los elementos universales del proceso de la comunicación propagandística" (p. 239).

El modelo parte de la definición de propaganda del propio autor, quien la entiende como

un fenómeno comunicativo de contenido y fines ideológicos mediante el cual un Emisor (individual o colectivo) transmite interesada y deliberadamente un Mensaje para conseguir, mantener o reforzar una posición de poder sobre el pensamiento o la conducta de un Receptor (individual o colectivo) cuyos intereses no coinciden necesariamente con los del Emisor (Pineda, 2006, p. 228).

El elemento fundamental del modelo es el poder $(P)$, ya que "los mensajes propagandísticos son la materialización de los objetivos de instancias de poder (partidos políticos, gobiernos, etc.) que pretenden conseguir, mantener o reforzar una posición de dominio sobre áreas clave de colectividades humanas" (Pineda, Barragán y Macarro, 2012, p. 53). El autor conceptualiza el propagado o PDO, que "puede ser una persona, una institución, una idea, una ley, un grupo, etc. Puede ser tanto el emisor interesado como una idea o acción del mismo, que se desean propagar; en definitiva, el PDO es el Emisor y/o lo que le rodea" (Pineda, 2006, p. 242). El propagado (PDO) delimita tres recorridos posibles del mensaje propagandístico, lo que da lugar a tres tipos de propaganda: propaganda de afirmación, cuando el mensaje se centra en el emisor; propaganda de reacción, cuando el propagado positivo se muestra como la solución ante la amenaza del propagado negativo; y propaganda de negación, que implicaría un mensaje que ólo se centra en el enemigo, haciendo ver sus características negativas (Pineda, Barragán y Macarro, 2012, p. 53). EI PDO estaría muy relacionado con otro elemento del modelo, el propagandema (PMA), "la unidad mínima de significación del 
mensaje propagandístico. (...) los elementos semánticos mínimos que responden al esquema (+)/(-)" (Pineda, 2006, pp. 254-255).

Los PMA se adaptan a las condiciones de recepción (CR), un concepto creado por el autor para englobar "todos aquellos elementos que sirven para ajustar el mensaje propagandístico a lo que piensa el receptor potencial de ese mensaje (estereotipos, actitudes, prejuicios, necesidades, circunstancias históricas, etc.)" (Pineda, Barragán y Macarro, 2012, p. 56). Estos pueden ser culturales (CR-C) o universales (CR-U). La diferencia entre ambos radica en su relación con una cultura concreta -en el primer caso-, o su carácter biológico e inherente a cualquier grupo social -el segundo tipo-.

\section{RESULTADOS: DESCRIPCIÓN DEL MODELO: COMPONENTES Y RELACIONES}

Con la elaboración de un modelo de análisis de la Propaganda Fotográfica pretendemos explicar las principales variables que entran en juego cuando el poder hace uso de una imagen fotográfica con intención propagandística. Para ello, debemos partir de la propia definición del término Propaganda Fotográfica; sin embargo, cuando se unen ambos conceptos -propaganda y fotografía-, se genera una confusión terminológica que se relaciona con el caos existente en torno al concepto genérico de propaganda.

De hecho, existe una gran cantidad de autores que aportan ejemplos muy valiosos sobre los usos propagandísticos de la imagen fotográfica (cfr. Jaubert, 1989; Taylor, 1990, 1998; Brugioni, 1999; López Mondéjar, 1999; Pantoja Chaves, 2006; Knightley, 2003; Sousa, 2003; Parejo Jiménez, 2004; McDonald, 2007; Pérez Gallardo, 2009; Sougez, M-L \& Pérez Gallardo, 2009; Huici, 2010, 2017); sin embargo, la gran mayoría no desarrolla una teoría sobre la Propaganda Fotográfica, al mismo tiempo que da por supuesta la definición del término.

Por este motivo, hemos decidido partir de Propaganda Fotográfica. La imagen al servicio del poder (Barragán-Romero, 2017), un manual que hace un recorrido por las principales aportaciones de la academia al mundo de la fotografía como herramienta de la propaganda, y que añade la única definición del concepto propuesta hasta el momento.

De este modo, para desarrollar un modelo de análisis de la Propaganda Fotográfica, entendemos que ésta puede definirse como:

Un fenómeno comunicativo de contenido y fines ideológicos mediante el cual un Emisor (individual o colectivo) genera y transmite un Mensaje deliberadamente haciendo uso de la imagen fotográfica con el propósito de conseguir, 
mantener o reforzar una posición de poder sobre el pensamiento o la conducta de un Receptor (individual o colectivo) (Barragán-Romero, 2017, p. 85).

Siguiendo esta definición, asumimos que la Propaganda Fotográfica se basa en dos componentes fundamentales: la ideología y el poder, elementos ya definidos por Pineda (2006) como inherentes a toda situación propagandística. Esta definición parte de que la emisión tiene más importancia que la recepción, evitando caer así en las interpretaciones individuales que en muchas ocasiones llevan a considerar que la Propaganda Fotográfica es cualquier fotografía manipulada, sin estudiar a priori la verdadera intencionalidad del emisor. Aunque asumimos que la recepción tiene una importancia significativa en la interpretación del mensaje y que el receptor está expuesto a situaciones de atención, percepción y retención selectiva, entendemos que para conocer si una fotografía está siendo utilizada propagandísticamente no es necesario tener en cuenta la recepción, sino la emisión, puesto que es en este lado de la balanza donde se genera el mensaje y el tándem ideología y poder. Los efectos del mensaje, por tanto, no entran a formar parte del modelo de análisis.

Por otra parte, cabe comentar que, aunque consideremos relevante el contenido ideológico de la fotografía para determinar si estamos ante un caso de propaganda, nuestra finalidad no es analizar la composición de la imagen, sino los temas ideológicos que se presentan en la misma y cómo los utiliza el emisor. Esto vuelve a llevarnos a la necesidad de analizar la Propaganda Fotográfica desde la emisión.

A continuación, mostramos la propuesta de modelización de la Propaganda Fotográfica:

\section{MODELO DE ANÁLISIS DE LA PROPAGANDA FOTOGRÁFICA}

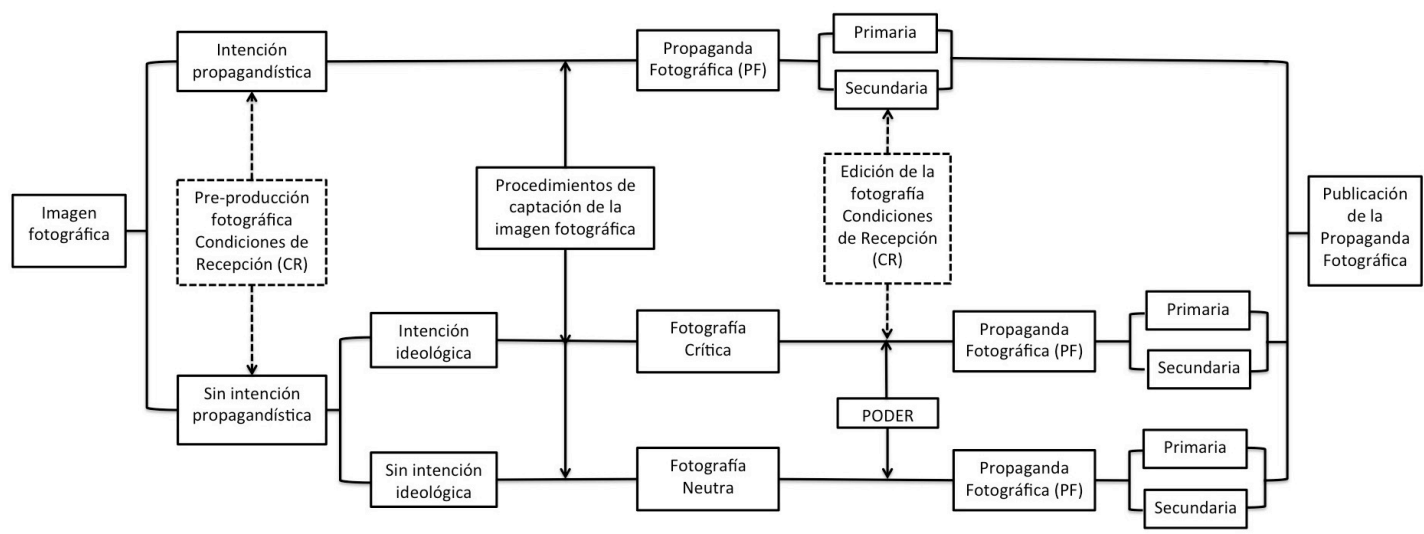

Figura 1. Propuesta de modelización de la Propaganda Fotográfica.

Fuente: Elaboración propia. 
El modelo presentado en la Figura 1 comienza con la intencionalidad propagandística inicial al emitir la imagen, pero suponiendo que no sólo puede existir Propaganda Fotográfica cuando ésta se da a priori, sino que cualquier imagen podría pasar a denominarse como tal siempre que aparezca la dualidad ideología-poder como una variable influyente en el proceso comunicativo. Las variables que entran en juego serían las siguientes:

a) Intencionalidad propagandística: el modelo parte de que la intencionalidad propagandística puede aparecer o no antes de capturar la fotografía. Es decir, el emisor propagandístico puede estar detrás de la toma de la imagen; o por el contrario, puede hacer uso de una fotografía que haya sido realizada a primera instancia sin intención propagandística. Para Pineda (2007, p. 114), lo fundamental de la propaganda se encuentra en sus objetivos y los fines que persigue. Esta intencionalidad concreta de conseguir, mantener o reforzar el poder, la diferencia de otros tipos de comunicación como la publicidad, cuya intención última es meramente comercial. De este modo, esta variable es fundamental para determinar la tipología de fotografías que se obtiene. Si existe, implica que el fotógrafo obtiene una fotografía con contenido ideológico que emitirá con la intención de conseguir, mantener o reforzar el poder. La ideología irá subordinada a la intencionalidad de poder. Como indica Pineda (2006, p. 196), en muchas ocasiones el mensaje propagandístico no contiene una fuerte carga ideológica. El autor apunta que "las apreciaciones sobre la sustancia de la propaganda deben entenderse -dado además el carácter borroso del concepto de ideología- en función del explicans de la propaganda: el poder" (2006, p. 196). Un ejemplo de falta de ideología en el contenido de la imagen lo podemos encontrar en una fotografía cualquiera de un candidato a la presidencia en la que aparezca compartiendo el tiempo junto a su familia. Esta estrategia tan usada del político humanizado no muestra los elementos ideológicos del partido, pero sirve para conseguir el poder. De este modo, la ideología va asociada inevitablemente al emisor último que se beneficia positivamente del mensaje.

b) Intencionalidad ideológica: las imágenes que son tomadas sin intención propagandística pueden tener un sentido ideológico, pero no necesariamente propagandístico. Este grupo se constituye por una gran cantidad de fotografías que han sido interpretadas erróneamente como propaganda a lo largo de la historia, al no tener en cuenta que la intencionalidad del fotógrafo tan sólo era ideológica, y no propagandística. Entendemos ideología "como un elemento determinante en la estructura social y política", ya que "el ámbito de la realidad al que se refiere la comunicación es precisamente lo que otorga un contenido diferenciador a la propaganda y lo que matiza un gran número de definiciones de propaganda puramente formales" (Pineda, 2006, p. 207). Un ejemplo de una imagen realizada con carga ideológica puede ser una fotografía realizada a los refugiados sirios que se encuentran congregados masivamente en el campo de refugiados de Idomeni (Grecia). Muchos son los reporteros que emiten conti- 
nuamente fotografías de esta situación social para criticar las estructuras de poder de la Unión Europea, pero sin la intencionalidad de conseguir ellos mismos ni otra instancia el poder.

Por otro lado, cuando no existe intencionalidad ideológica por parte del fotógrafo, las imágenes podrían considerase neutras, ya que de ellas no formarían parte ni la ideología ni el poder. Partimos de que toda imagen fotográfica muestra un punto de vista acerca de la sociedad, pero no por ello debemos considerar que todas pasen necesariamente a ser una crítica ideológica. En este punto podríamos hablar de todas las fotografías que se realizan sin una intención ideológica y/o propagandística. Como ejemplos podemos considerar las imágenes que colman los álbumes familiares, y una gran parte de las que circulan por las redes sociales y muestran fiestas, reuniones de grupos, parejas, así como selfies del propio individuo que las emite. Podemos decir, por tanto, que hay múltiples intenciones comunicativas. Si tenemos en cuenta el concepto de ideología ya mencionado, en el que entran en relación elementos de la estructura social y política, vemos cómo no puede considerarse que todas las imágenes fotográficas contengan ideología, ya que gran parte de ellas no refieren a estos temas.

Como resumen de estas dos variables, podemos decir que en función de la intencionalidad primera al obtener la imagen, esto es, de su relación con la ideología y el poder, obtendremos tres tipos de fotografías posibles a priori: Propaganda Fotográfica, Fotografía Crítica y Fotografía Neutra. Siempre y cuando la ideología y la intención de poder estén presente en la fotografía desde el principio, estaremos hablando de Propaganda Fotográfica. Sin embargo, si en las condiciones de emisión que rodean al fotógrafo únicamente actúa el componente ideológico, estaremos ante un ejemplo de lo que denominamos Fotografía Crítica, entendiendo por tal toda imagen fotográfica capturada con pretensiones ideológicas por parte del fotógrafo que la realiza, pero sin una intencionalidad de mantener, conseguir o reforzar el poder; antes al contrario, y en lugar de ser un producto pro-poder, la Fotografía Crítica sirve para elaborar, valga la redundancia, una crítica del poder. En tercer lugar, si la fotografía se produce en condiciones de emisión donde ni la ideología (ya sea pro- o anti-poder) ni la intención comunicativa de poder juegan un papel, la imagen podría conceptualizarse como Fotografía Neutra.

c) Pre-producción fotográfica: esta variable se constituye como un elemento opcional a toda captura fotográfica, y hace alusión a que, en algunas ocasiones, la imagen se estructura y compone antes de ser registrada en el objetivo. Si tomamos en cuenta algunas de las formas de manipulación de las que habla Scot Macdonald (2007), podemos destacar entre ellas la escenificación; esto es, cuando se cuidan los detalles de la puesta en escena antes de tomar la foto. En el sentido en que para escenificar una fotografía hay que alterar el lugar donde se realiza la imagen, suponemos que este 
elemento entraría a formar parte de la variable que tratamos, la pre-producción fotográfica. Un ejemplo son las imágenes realizadas a los candidatos políticos para las campañas electorales. Estas fotografías son pensadas por el equipo de campaña; el candidato es sometido a maquillaje, y la toma de la imagen se realiza normalmente en un estudio, cuidando cualquier tipo de detalle.

En este punto referido a la pre-producción entrarían un sinfín de variables, siempre y cuando tengan que ver con la planificación de la imagen que tiene lugar antes de que ésta sea capturada. Para poder analizar estos aspectos, sería imprescindible contar con el testimonio de la persona o el equipo encargado de capturar la imagen. A fin de cuentas, podría resumirse en si existe una pre-producción previa a la toma de la imagen o ha sido una captura instantánea.

Sin embargo, más que aspectos técnicos, lo que nos interesa aquí es destacar las Condiciones de Recepción (CR), establecidas por Pineda (2006). Como ya se comentó cuando mencionamos el modelo del autor, las CR-U serían aquellas de carácter biológico e inherentes a cualquier grupo social, y las CR-C estarían relacionadas con una cultura concreta. De este modo, consideramos que el fotógrafo, antes de tomar la imagen, puede tener en cuenta estas condiciones de recepción para ajustar el mensaje al punto de vista o las características del receptor. Así, en una campaña política, si se considera que algún aspecto folclórico es relevante para conectar con el target, las fotografías pueden y suelen mostrarlos. Del mismo modo, si se considera que un tema que conecta con el receptor es el hambre, o la seguridad -aspectos que se englobarían dentro de las condiciones de recepción universales-, la fotografía incluiría este tipo de mensaje.

e) Procedimientos de captación de la imagen fotográfica: cualquier tipo de imagen fotográfica, sin importar la intencionalidad ni los condicionamientos estructurales y sociales con que haya sido realizada, muestra un trozo de la realidad. Esta realidad es capturada mediante unos procedimientos concretos: iluminación, punto de vista, campo/fuera de campo, planos, enfoque y movimiento, entre otros. Estos elementos están presentes siempre que una persona realiza una fotografía, ya que todos ellos se ponen en juego en ese mismo instante. Aunque no es nuestra intención entrar en aspectos técnicos, hemos de tomar en consideración que, justo en el momento de capturar una imagen, el fotógrafo toma una serie de decisiones. De este modo, consideramos que dentro de los procedimientos de captación de la imagen fotográfica, aparecerían, entre muchas otras, las siguientes variables: iluminación, selección del punto de vista, campo y fuera de campo, tipos de planos (plano panorámico, general, americano, medio, primer plano, detalle), enfoque y movimiento. De esta forma, las condiciones técnicas de captación tienen cabida en nuestro modelo. 
f) El poder como variable transformadora: aunque la intencionalidad del fotógrafo no haya sido propagandística a priori, las organizaciones que persiguen el poder pueden hacer uso de cualquier tipo de imagen y emplearla como Propaganda Fotográfica. Lo realmente interesante de la fotografía es que cualquier Fotografía Crítica o Fotografía Neutra puede ser usada por un emisor con intencionalidad de poder. En estos casos, aunque las fotografías no hayan sido concebidas con intencionalidad propagandística, una vez son reutilizadas por una instancia con pretensiones de poder, pasarían a denominarse Propaganda Fotográfica. Esto explica que tanto las imágenes críticas antipoder como las fotografías neutras y apolíticas a priori, una vez son instrumentalizadas por el poder, puedan pasar a denominarse Propaganda Fotográfica. En este punto, el modelo admite el análisis de los procedimientos mediante los cuales las instancias de poder pueden resemantizar un mensaje y transformarlo en otro, con una intención muy distinta a la original. Siguiendo a Victorino Zecchetto (2011), asumimos que

resemantizar es un vocablo que se refiere a la operación semiótica de transformar el sentido de una realidad conocida o aceptada para renovarla o para hacer una transposición de modelo, creando una entidad distinta, pero con alguna conexión referencial con aquélla, de modo que esta última asume un nuevo significado que la primera no tenía (Zecchetto, 2011, p. 127).

En el modelo, la acción transformadora del poder se puede contemplar en este punto:

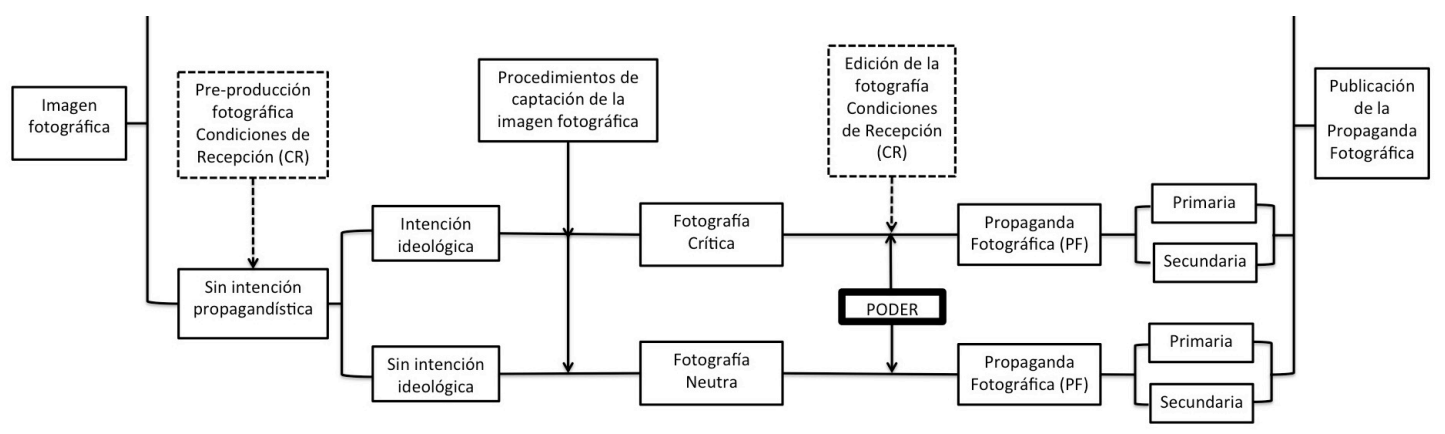

Figura 2. Procesos de resemantización de la fotografía causados por el poder.

Fuente: Elaboración propia.

Como comentábamos anteriormente, el contenido ideológico de la imagen se explica a partir del poder. Es por ello por lo que muchos mensajes de distintos candidatos políticos no contienen ideología, pero son considerados propaganda gracias a la finalidad que persiguen. De este modo, cualquier imagen puede ser Propaganda Fotográfica siempre que sea utilizada por un emisor con intención de poder, emisor que llevaría consigo una carga ideológica determinada. Por otro lado, una imagen crítica podría 
seguir utilizando su discurso originario, o bien cambiar totalmente de ideología. Esto podría darse, por ejemplo, si un partido de extrema derecha hace uso de la imagen tomada por Robert Capa en Cerro Muriano para conseguir sus propósitos propagandísticos. Aunque la imagen fuese tomada por el fotógrafo con un contenido ideológico claramente prorrepublicano, la resemantización de la fotografía la dotaría de un contenido ideológico contrario. Imaginemos que la imagen se utiliza tal y como fue publicada en origen, pero a ella se le añade un texto pro-fascista y un logo de un emisor de extrema derecha. En este caso, la ideología sería totalmente contraria a la inicial, y a esta nueva ideología iría asociada una intencionalidad de poder concreta, resemantizando por completo la fotografía tomada por Capa en Cerro Muriano.

De este modo, vemos cómo el fotógrafo de la imagen no tiene por qué coincidir con el emisor de la propaganda. Es por ello por lo que hemos decidido considerar esta tipología de imágenes que nos permitan dilucidar que el emisor de la propaganda es el ente realmente importante a analizar. Sólo en el caso de las fotografías que son realizadas con intencionalidad propagandística es posible la coincidencia entre fotógrafo y emisor de la propaganda. Hablamos de "posible" porque entendemos que el emisor de la propaganda raramente toma las imágenes, ya que estas son capturadas por una persona o un grupo encargado de gestionar esta parcela de su comunicación propagandística. No obstante, este hecho no tiene relevancia, puesto que las fotografías sirven al poder desde sus inicios. Los casos que requerirían más análisis, por tanto, son aquellos en los que el fotógrafo de la imagen y el emisor de la propaganda no coinciden ni forman parte del mismo grupo que desarrolla la propaganda.

g) Edición de la fotografía: aunque en el modelo de análisis esta variable esté relegada a un segundo plano, conviene destacar su importancia, puesto que en la gran mayoría de los estudios, el concepto de manipulación es clave, estando siempre vinculado al de propaganda. De hecho, la mayor parte de los autores se centra en este aspecto concreto, dejando de lado otro que, a nuestro parecer, resulta de una relevancia mayor: la vinculación con el poder. El panorama teórico actual, por tanto, da una gran importancia a la manipulación de la fotografía por parte del poder e, incluso, del fotógrafo; sin tener en cuenta que muchas veces la propaganda hace uso de imágenes que son fieles reflejos de la realidad, y no producto de la manipulación. El modelo de análisis que proponemos refleja la edición de la fotografía, posterior a la toma de la imagen, como una variable opcional, que puede o no estar presente siempre que hablamos de Propaganda Fotográfica. Dentro de este punto cabrían todas las técnicas que se utilizan una vez que la imagen ha sido capturada, y entrarían todas las pertenecientes tanto al período analógico como al digital. Actualmente, las tecnologías digitales han multiplicado los usos de este tipo de manipulaciones fotográficas. Si en la fotografía analógica se hablaba de la manipulación sobre el negativo, la fotografía digital permite multitud de manipulaciones a través de herramientas informáticas, así co- 
mo en aplicaciones móviles y en las propias cámaras digitales. Las redes sociales en sí mismas permiten modificar las imágenes una vez capturadas. Este es el caso de Facebook o Instagram, que tienen disponibles filtros para el usuario que cambian la apariencia de la fotografía y son usados habitualmente. Además de estos filtros, estas aplicaciones dan la opción de enfocar o desenfocar ciertas zonas de la imagen, así como cambiar la basculación del horizonte.

Del mismo modo, como estamos ante un modelo sobre el proceso de la Propaganda Fotográfica, y no sobre la composición de la misma, consideramos innecesario establecer una categorización fija sobre la manipulación de la imagen. Asimismo, la tarea de categorización de esta variable es compleja no sólo por la infinita cantidad de aspectos a tener en cuenta, sino también por la cuestión temporal y el desarrollo tecnológico: no es lo mismo la manipulación que tenía lugar en el siglo XIX que la que ocurre en nuestros días. Es por ello que sólo vemos la necesidad de comentar si existe manipulación o no para servir a los propósitos de la propaganda, pero no consideramos necesario marcar una tipología de manipulaciones.

h) Propaganda Fotográfica primaria o secundaria. Pineda (2005, p. 612) apunta que existen dos tipos de propaganda según el emisor: propaganda primaria y propaganda secundaria. Mientras que la propaganda primaria sería aquella en la que "la instancia de poder propagada emite el Mensaje", en la secundaria el mensaje es emitido por un grupo o individuo que conscientemente se pone al servicio de la fuente de poder propagada. Estamos por tanto ante dos tipos de emisores: el propagandista primario y el propagandista secundario. El primario es aquel "grupo o individuo que detenta el poder y al que beneficia en última instancia la producción de propaganda"; y el propagandista secundario "es un emisor propagandista consciente de la instancia de poder a la que favorece su comunicación, pero no es el detentador último del poder". Pineda (2005, pp. 567-568) apunta que "los propagandistas secundarios pueden ser profesionales de la comunicación de masas, artistas o intelectuales que se ponen al servicio directo y consciente de una instancia propagandista primaria, articulando mensajes según las directrices ideológicas proporcionadas por ésta".

Aplicando esta teoría a la Propaganda Fotográfica, llegamos a la conclusión de que también es necesario considerar estos dos tipos. Así, se considera Propaganda Fotográfica primaria a la imagen emitida directamente por el grupo o individuo que detenta o busca el poder y Propaganda Fotográfica secundaria a la emitida por un grupo o individuo que se pone conscientemente al servicio del beneficiario último de este mensaje. Por ejemplo, si un partido político emite una fotografía en sus redes sociales del candidato a la presidencia, estaríamos ante un caso de Propaganda Fotográfica primaria, ya que el mensaje muestra a la persona y a la organización que busca el poder. Por otro lado, si un ciudadano comparte una imagen de este mismo candidato en sus 
redes sociales mostrando su apoyo, podemos considerar que nos encontramos ante un ejemplo de Propaganda Fotográfica secundaria, puesto que el emisor de la fotografía -que puede ser el fotógrafo de la imagen o no- no es el detentador último del poder, pero es consciente de que su mensaje ayuda al partido a conseguirlo.

i) Publicación de la Propaganda Fotográfica: la fotografía siempre está vinculada a otros medios de comunicación de masas que la hacen circular, por lo que la Propaganda Fotográfica depende de su publicación en distintos medios para llegar al receptor final. En sus inicios, y cuando las condiciones tecnológicas lo permitieron, la fotografía comenzó haciendo uso de la prensa y la cartelería. Los años treinta dieron a la fotografía una importancia fundamental con el nacimiento del fotoperiodismo moderno. Las imágenes fotográficas comenzaron a llenar las páginas de revistas a todo color. La llegada de la televisión dio protagonismo a la imagen en movimiento, aunque esto no evitó que la fotografía continuara su curso. De hecho, Internet nos demuestra que la fotografía está más viva que nunca, ya que se ha convertido en un medio fundamental para la expresión de la cultura occidental. Todos los usuarios de las redes sociales comparten fotografías continuamente. El ser humano del siglo XXI está acostumbrado a la facilidad de captura de la imagen fotográfica, lo que le permite retener cualquier instante decisivo. Estas imágenes circulan por la red y son resemantizadas en multitud de ocasiones, sobre todo gracias a la colaboración de la gran cantidad de personas que se encuentran en el universo online y ayudan a compartir y reelaborar los mensajes. Estamos, pues, en un círculo masivo de imágenes que son emitidas y compartidas por millones de personas al mismo tiempo, lo que nos dificulta en gran parte de las ocasiones la tarea de búsqueda del autor principal de la imagen; un hecho que, por cierto, tiene implicaciones metodológicas directas para el modelo aquí planteado.

Esta variable de la publicación de la Propaganda Fotográfica es similar a la variable propuesta por Jowett y O'Donnell (2012, p. 363) en su modelo y que hace referencia a los medios de comunicación seleccionados por el propagandista (Media Methods). En este punto los autores también señalan que las nuevas tecnologías son el factor que más ha afectado a este aspecto, tanto cualitativa como cuantitativemente. Es por ello por lo que Jowett y O'Donnell (2012, p. 364) avisan de los peligros que supone Internet por la facilidad de acceso y difusión de información, que permite a una persona llegar a multitud de receptores en segundos. La fotografía necesita inevitablemente de otros medios para llegar al ciudadano, lo que hace necesaria la selección del soporte adecuado por parte del propagandista. Aquí entrarían elementos económicos y contextuales, puesto que no todos los partidos políticos cuentan con los mismos recursos ni llegan a su público objetivo de la misma manera si usan uno u otro canal. Las redes sociales se presentan como la herramienta más efectiva para los partidos nuevos, ya que estos no tienen financiación pública y les cuesta llegar a los grandes medios de masas. 
Del mismo modo, el medio en el que se publica una imagen afecta necesariamente a las condiciones de emisión. No es lo mismo encontrar una imagen del Presidente del Gobierno en la página web oficial del partido político al que pertenece, que encontrar esta misma fotografía en la red social del partido contrario o en una red social de un ciudadano que la hace circular apoyando o criticando el mensaje. El medio seleccionado, por tanto, está vinculado al contexto socio-histórico en el que nos encontremos, y dependerá tanto de la intencionalidad y los recursos del emisor, como de los receptores que descodifican el mensaje.

Podemos resumir este punto diciendo que, cuando una imagen fotográfica es utilizada como Propaganda Fotográfica, se publica en distintos medios para llegar al público al que va dirigida. Las características del emisor de la propaganda y de los receptores a los que se dirige determinará la selección del medio masivo en el que irá inserta la Propaganda Fotográfica.

Para ejemplificar de manera breve la teoría propuesta, hemos utilizado una fotografía de Pablo Casado, candidato a la Presidencia de España por el Partido Popular y actual líder de la oposición (Figura 3). La fotografía fue publicada el 4 de junio de 2019 en su cuenta oficial de Instagram, @pablocasadoblanco. En ella aparece el político con mirada al frente. Detrás de él se sitúa la bandera de España. El texto que acompaña a esta fotografía dice: "Vamos a explorar todos los escenarios posibles. Los españoles quieren unión, libertad, estabilidad y gobernabilidad, y eso es lo que ofrecemosen el @partidopopular."

Esta fotografía, al estar localizada en la cuenta oficial de un político, podría pasar a denominarse directamente Propaganda Fotográfica primaria, ya que sólo habla de las cualidades del emisor. El contexto nos hace entender que ha sido tomada por su equipo de comunicación, ya que el propio candidato aparece en la imagen. No obstante, estos datos no podríamos corroborarlos a no ser que mantuviésemos una entrevista con las personas responsables de su imagen digital. El contenido de la fotografía, unido al texto, nos hace presuponer que la imagen ha pasado por el primer proceso de generación de la Propaganda Fotográfica, en el que las fotografías son tomadas directamente para servir a fines propagandísticos. Estamos ante un ejemplo en el que se han tenido en cuenta las condiciones de recepción de la imagen, ya que en el texto podemos leer elementos que refieren al contexto actual, en el que los principales partidos votados por los españoles aún no han formado gobierno tras las elecciones generales del 28 de abril de 2019. La bandera de España que aparece en la imagen, junto a los términos "unión, libertad, estabilidad, gobernabilidad", dejan entrever elementos ideológicos afines al Partido Popular, muy defensor de la unión de España y contrario al discurso protagonizado por la independencia catalana. 
Asimismo, probablemente nos encontramos con un caso en el que se han tenido en cuenta los elementos de pre-producción a la hora de la toma de la imagen, sólo basta con ver el plano y la mirada del candidato, así como la bandera de España que se sitúa tras él. También podemos considerar que la edición ha tenido lugar, ya que Instagram pone a disposición de los usuarios una gran cantidad de filtros y técnicas de edición de imagen.

A la hora de publicar esta fotografía, la red social Instagram es un canal idóneo, ya que actualmente está siendo utilizada por la mayor parte de los partidos políticos tanto en el escenario nacional como internacional. De hecho, son muchos los estudios que ya han analizado esta plataforma digital como herramienta de comunicación política (Ekman \& Widholm, 2017; Lalancette \& Raynauld, 2017; Liebhart \& Bernhardt, 2017; Muñoz \& Towner, 2017; Selva-Ruiz \& Caro-Castaño, 2017; Russmann \& Svensson, 2017; Verón Lassa \& Pallarés Navarro, 2017; López-Rabadán \& Doménech-Fabregat, 2018).

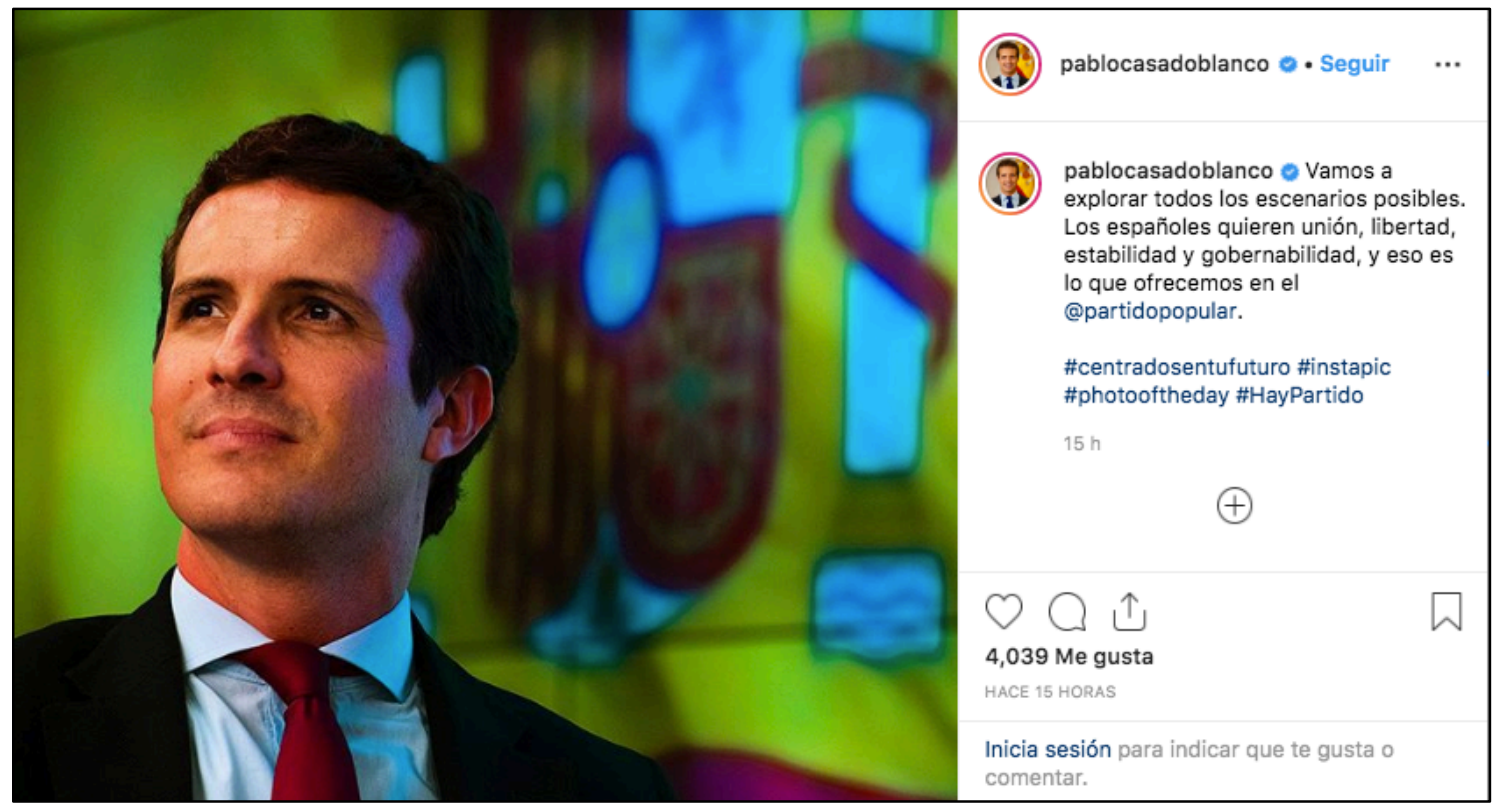

Figura 3. Fotografía publicada en la cuenta de Pablo Casado, @pablocasadoblanco. Fuente: Instagram.

\section{DISCUSIÓN Y CONCLUSIONES}

Tras explicar el modelo de análisis del proceso de generación de la Propaganda Fotográfica, consideramos que la aportación principal presentada es que esta herramienta desvincula los usos propagandísticos de la fotografía de los casos de manipulación de la imagen. Al centrar el enfoque en el emisor último de la imagen fotográfica y no en el 
contenido de la misma, este estudio abre nuevas vías de investigación que pueden centrarse no sólo en contextos bélicos y dictatoriales, sino en la propaganda que se da en sociedades democráticas, sobre todo a través de redes sociales, que son los vehículos más utilizados actualmente.

De este modo, aunque la mayor parte de los estudios académicos sobre Propaganda Fotográfica se centren en las relaciones sobre manipulación y realidad, el modelo de análisis propuesto demuestra que la manipulación de la imagen no es condición sine qua non para determinar si una fotografía está siendo utilizada de manera propagandística. De hecho, muchas imágenes que muestran una parcela de la realidad pueden servir a los fines de las élites de poder tanto o más que cualquier fotografía manipulada.

Asimismo, esta herramienta tiene una capacidad analítica atemporal, esto es, contribuye el análisis de las fotografías más allá del periodo histórico en el que se ubican las imágenes. Los medios de comunicación de masas han hecho uso de la fotografía desde su nacimiento. Si en el siglo XIX y XX el protagonismo estuvo en las manos de los periódicos, en el siglo XXI es internet el medio protagonista, con el uso de la imagen por parte de redes sociales como Twitter, Pinterest, Instagram, Facebook, etc. Una de las redes más interesantes en el plano fotográfico es Instagram. Su interés reside en la capacidad de unir texto e imagen en una sola publicación y la posibilidad de etiquetar dicho mensaje mediante hashtags. Estos hashtags utilizan el símbolo de la almohadilla (\#), creando así un enlace directo a todos los mensajes relacionados con dicha etiqueta. La gran cantidad de imágenes fotográficas que circula actualmente en las redes sociales y su uso por parte de líderes políticos delata aún más la necesidad de comprender cuándo nos encontramos ante un caso de propaganda y cuál es el fin último de ese mensaje. Sin embargo, esta amplia circulación nos lleva a una de las limitaciones del modelo: la falta de información sobre el auténtico fotógrafo de la imagen. La falta de datos respecto a los autores originales de la imagen, en gran parte de los casos, hace complicada la identificación de la intencionalidad primaria del emisor. Así, se complica el análisis del verdadero proceso que ha seguido la imagen hasta pasar a ser considerada Propaganda Fotográfica.

No obstante, a pesar de esta complicada tarea (que supone conseguir información sobre la persona que capta la imagen), una vez es instrumentalizada por el poder, podemos considerarla Propaganda Fotográfica, aunque no sepamos exactamente cuál es el proceso que ha seguido la fotografía al no tener datos sobre el verdadero autor. En otras palabras, la disponibilidad de información sobre las condiciones de generación de un caso concreto de propaganda puede influir en la aplicabilidad de las unidades y relaciones del modelo. 
Por otro lado, una segunda limitación que encontramos en el modelo de análisis es la gran cantidad de variables que maneja. Siguiendo a Rodrigo Alsina (2007) y Willer (1969), llegamos a la conclusión de que un modelo simplifica el fenómeno en sus variables más representativas. No obstante, la tarea se convierte en ardua y complicada cuando entran en juego tantos elementos. Somos conscientes de que, a pesar de la complejidad del modelo, hemos dejado de lado una gran cantidad de cuestiones técnicas y compositivas que resultan fundamentales dentro del campo de la teoría de la imagen. No obstante, nos gustaría incidir en que éste es un modelo de los procesos de emisión de la Propaganda Fotográfica, y no de la composición de la misma. Mediante la modelización que proponemos, la propaganda se analiza teniendo en cuenta el ente que emite el mensaje, y ésta es la teoría que hemos aplicado al análisis de la Propaganda Fotográfica. Así, y aunque consideramos que no son necesarias más variables para determinar si una fotografía está siendo usada como propaganda, la modelización propuesta puede ser perfectamente complementada por construcciones teóricas que enriquezcan el análisis del contenido de la imagen.

Por último, una tercera limitación del modelo es la relativa a la recepción de la fotografía. Como hemos señalado en varias ocasiones, la mayor parte de las teorías de la imagen se centran en la recepción de la misma. Nuestro modelo, por el contrario, es un modelo de análisis de la emisión de la fotografía como herramienta de la propaganda, basado en la definición de Propaganda Fotográfica desarrollada por BarragánRomero (2017), que a su vez tiene su origen en la definición de propaganda aportada por Pineda (2006). Por ello, el modelo sólo establece el análisis de la parcela de la emisión para poder considerar si una fotografía es Propaganda Fotográfica. Esto no quiere decir, sin embargo, que ignoremos la existencia del contenido del mensaje y la actitud participativa del receptor en el proceso. Es más, asumimos que una misma imagen puede ser descodificada de distintas maneras por los receptores, teniendo efectos en unos y no en otros. Pero esta disparidad de opiniones no nos ayudaría a determinar el uso propagandístico de la fotografía; todo lo contrario, nos sumiría en un caos analítico debido a la subjetividad de los receptores. Es por ello por lo que el modelo de análisis propuesto sólo determina el estudio de la etapa emisora.

En conclusión, podemos afirmar que la gran masa de fotografías que asedia a los receptores diariamente a través de los medios, sobre todo en la parcela digital, hace necesaria la aplicabilidad de este modelo, que centra su enfoque en la finalidad última de la instancia emisora. Por ello, este estudio abre nuevas vías de investigación centradas, fundamentalmente, en la gran cantidad de imágenes que colapsan la sociedad actual. Si centramos el punto de vista en el emisor último de las mismas, podremos saber si estamos ante un caso de Propaganda Fotográfica, más allá del contenido (manipulado o no) de la fotografía en cuestión. 


\section{Referencias}

Barragán-Romero, A. I. (2017). Propaganda Fotográfica. La imagen al servicio del poder. Sevilla: Advook.

Bourdieu, P. (coord.) (1979). La fotografía: un arte intermedio. México: Nueva Imagen.

Bourdieu, P. (2003). La definición social de la fotografía. En Bourdieu, P., Un arte medio: ensayo sobre los usos sociales de la fotografía (pp. 135-172). Barcelona: Gustavo Gili.

Brugioni, D. A. (1999). Photo Fakery. The history and techniques of photographic deception and manipulation. Virginia: Brassey's.

Chomsky, N. \& Herman, E. S. (2005). Los guardianes de la libertad. Barcelona: Crítica.

De Moragas, M. (ed.) (1993). Sociología de la comunicación de masas. Il. Estructura, funciones y efectos. Barcelona: Gustavo Gili.

Ekman, M. \& Widholm, A. (2017). Political communication in an age of visual connectivity: Exploraing Instagram practices among Swedish politicians. Northern Lights: Film \& Media Studies Yearbook, 15(1), pp. 15-32. DOI: 10.1386/nl.15.1.15_1

Freund, G. (1983). La fotografía como documento social. Barcelona: Gustavo Gili.

Huici, A. (2010). Guerra y propaganda en el siglo XXI. Nuevos mensajes, viejas guerras. Sevilla: Alfar.

Huici, A. (2017). Teoría e Historia de la Propaganda. Madrid: Síntesis.

Jaubert, A. (1989). Making people dissapear. An amazing chronicle of photographic deception. New York: Pergamon-Brassey's.

Jowett, G. S. \& O'Donnell, V. (2012). Propaganda and persuasion (Fifth Edition). Newbury Park: Sage.

Knightley, P. (2003). The first casualty. The war correspondent as hero, propagandist and mythmaker from the Crimea to Iraq. London: André Deutsch.

Lalancette, M. \& Raynauld, V. (2017). The Power of Political Image: Justin Trudeau, Instagram, and Celebrity Politics. American Behavioral Scientist, pp. 1-37. DOI: 10.1177/0002764217744838

Lasswell, H. D. (1993). Estructura y función de la comunicación en la sociedad. En De Moragas, M. (ed.), Sociología de la comunicación de masas. II. Estructura, funciones y efectos (pp. 50-68). Barcelona: Gustavo Gili. 
Liebhart, K. \& Bernhardt, P. (2017). Political Storytelling on Instagram: Key Aspects of Alexander Van der Bellen's Successful 2016 Presidential Election Campaign. Media and Communication, 5(4), pp. 15-25. DOI: 10.17645/mac.v5i4.1062

López Mondéjar, P. (1999). 150 años de fotografía en España. Barcelona: Lunwerg.

López-Rabadán, P. \& Doménech-Fabregat, H. (2018). Instagram y la espectacularización de las crisis políticas. Las $5 \mathrm{~W}$ de la imagen digital en el proceso independentista de Cataluña. El profesional de la información, 27(5), pp. 1013-1029. DOI: 10.3145/epi.2018.sep.06

Macdonald, S. (2007). Propaganda and Information Warfare in the Twenty-First Century. Altered images and deception operations. Great Britain: Routledge.

Muñoz, C. L. \& Towner, T. L. (2017). The Image is the Message: Instagram Marketing and the 2016 Presidential Primary Season. Journal of Political Marketing, 16(3-4), pp. 290-318. DOI: $10.1080 / 15377857.2017 .1334254$

Parejo Jiménez, N. (2004). Fotografía y guerra. En Pena, A. (coord.), Comunicación y guerra en la historia (pp. 167-181). Santiago de Compostela: Tórculo Edicións.

Pérez Gallardo, H. (2009). El reportaje gráfico. En Sougez, M-L (coord.) [et. al], Historia general de la fotografía (pp. 367-492). Madrid: Cátedra.

Pineda, A. (2001). El modelo de propaganda de Noam Chomsky: medios mainstream y control de pensamiento. Ámbitos, 6, pp. 191-210.

Pineda, A. (2005). Elementos para una teoría comunicacional de la propaganda. Tesis Doctoral. Departamento de Comunicación Audiovisual, Publicidad y Literatura. Universidad de Sevilla.

Pineda, A. (2006). Elementos para una teoría comunicacional de la propaganda. Sevilla: Alfar.

Pineda, A. (2007). Propaganda y publicidad comercial: un principio diferenciador. Questiones Publicitarias, 1 (12), pp. 107-128.

Pineda, A.; Barragán Romero, A. I. \& Macarro, A. (2012). Semiótica de la propaganda: aplicación empírica de un modelo de análisis formal a portadas de prensa de la Guerra Civil Española. Análisi, 46, pp. 49-68.

Rodrigo Alsina, M. (2007). Los modelos de la comunicación (Segunda Edición). Madrid: Tecnos.

Russmann, U. \& Svensson, J. (2017). Interaction on Instagram? Glimpses from the 2014 Swedish Elections. International Journal of E-Politics, 8(1), pp. 50-66. DOI: 10.4018/IJEP.2017010104 
Selva-Ruiz, D. \& Caro-Castaño, L. (2017). Uso de Instagram como medio de comunicación política por parte de los diputados españoles: la estrategia de humanización en la "vieja" y la "nueva" política. El profesional de la información, 26(5), pp. 903-915.

Sontag, S. (2009). Sobre la fotografía. Barcelona: Debolsillo.

Sontag, S. (2010). Ante el dolor de los demás. Barcelona: Debolsillo.

Sougez, M-L \& Pérez Gallardo, H. (2009). Arte y fotografía (II). Las vanguardias y el periodo de entreguerras. En Sougez, M-L (coord.) [et. al], Historia general de la fotografía (pp. 299366). Madrid: Cátedra.

Sousa, J. P. (2003). Historia crítica del fotoperiodismo occidental. Sevilla: Comunicación Social.

Taylor, P. M. (1990). Munitions of the mind. War propaganda from the ancient world to the nuclear age. Glasgow: PSL.

Taylor, P. M. (1998). War and the media. Manchester: Manchester University Press.

Verón Lassa, J. J. \& Pallarés Navarro, S. (2017). La imagen del político como estrategia electoral: el caso de Albert Rivera en Instagram. Mediatika, 16, pp. 195-217.

Willer, D. (1969). La sociología científica. Teoría y Método. Buenos Aires: Amorrortu.

Zecchetto, V. (2011). El persistente impulso a resemantizar. Universitas, 14, pp. 127-142. 